\title{
Role of PKC-delta as a signal mediator in epidermal barrier homeostasis
}

\author{
Bong Kyun Ahn · Se Kyoo Jeong • Seung Hun Lee
}

Received: 3 October 2006 / Revised: 16 January 2007 / Accepted: 16 January 2007 / Published online: 14 February 2007

(C) Springer-Verlag 2007

\begin{abstract}
The skin shows an important "epidermal permeability barrier homeostasis" in response to barrier disruption. Calcium ion $\left(\mathrm{Ca}^{2+}\right)$, a major regulator in keratinocyte differentiation and proliferation, plays a crucial role in skin barrier homeostasis. Acute barrier disruption induces an immediate depletion of both extra- and intracellular calcium ions in the epidermis, especially in the upper granular layers, and results in the loss of normal epidermal calcium gradient. Currently, we hypothesize that the change in the intracellular calcium ion concentration triggers the barrier repair responses, such as lamellar body (LB) secretion and increased lipid synthesis in the epidermis. In this article, we suggest that PKC-delta is a signaling mediator for the changes in extracellular and intracellular calcium ion concentration.
\end{abstract}

Keywords Epidermal calcium gradient $\cdot$ PKC-delta · $\mathrm{PKC}$ inhibitor $\cdot$ Skin barrier $\cdot$ Rottlerin

\footnotetext{
B. K. Ahn

Department of Dermatology,

Armed Forces Capital Hospital, Sungnam, South Korea

S. K. Jeong · S. H. Lee

BK21 Project for Medical Sciences,

Yonsei University, Seoul, South Korea

S. K. Jeong

NeoPharm Co. Ltd., Daejeon, South Korea

S. H. Lee $(\square)$

Department of Dermatology, Yongdong Severance Hospital,

Yonsei University College of Medicine, 146-92, Dogok-dong,

Kangnam-gu, Seoul 135-720, South Korea

e-mail:ydshderm@yumc.yonsei.ac.kr
}

\author{
Abbreviations \\ PKC Protein kinase $\mathrm{C}$ \\ $\left[\mathrm{Ca}^{2+}\right]_{\mathrm{I}} \quad$ Intracellular free calcium concentration \\ $\left[\mathrm{Ca}^{2+}\right]_{\mathrm{o}} \quad$ Extracellular free calcium concentration \\ SG Stratum granulosum \\ PMCA Plasma membrane calcium-adenosine \\ triphosphatase \\ DAG Diacylglycerol \\ LB Lamellar body
}

Homeostasis is a fundamental process by which living organisms stably maintain their internal conditions against external environmental changes. To maintain homeostasis, our bodies conduct multiple dynamic equilibrium adjustments, tightly controlled by closely interrelated regulatory mechanisms. Most of the homeostatic systems working in our body are comprised of three components: receptors, signal transducers and effectors (Fig. 1a). The first components, receptors, sense and report changes in the external environment. The second components, signal transducers, convert and magnify the receptor's signals into another transducer and/or effector. This process, referred to as 'signal transduction', generally involves a sequence of biochemical reactions inside the cell, which are carried out by enzymes or linked through second messengers. The last one is the effectors, which show the 'responses' by eliciting the appropriate cellular changes in response to the environmental changes.

Most viable organs have homeostatic control systems. For example, the pancreas produces insulin and glucagon to control blood-sugar concentration. The lungs take in oxygen and give off carbon dioxide. The kidneys remove urea, and adjust the concentrations of water and a wide variety of ions. 
Fig. 1 a Three components of the homeostatic control system: the receptors, the signal transducers and the effectors, b barrier repair response and c calcium control system in keratinocytes

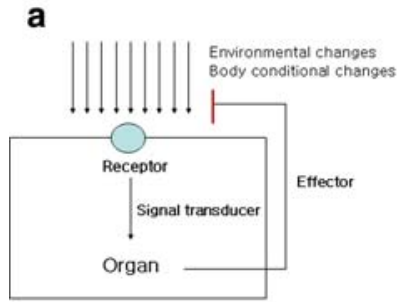

c
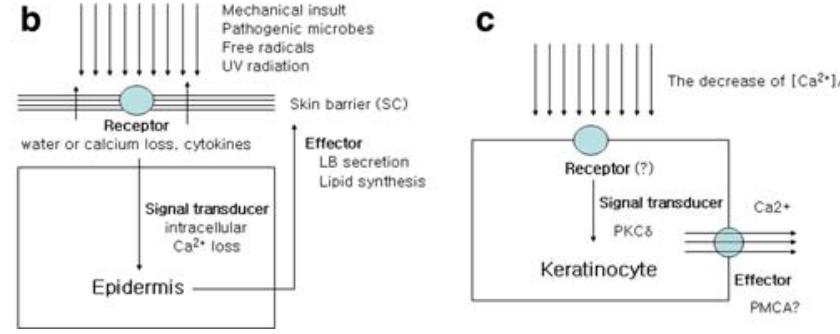

The skin is the largest and the outermost organ of the human body. Skin controls transcutaneous water movement, protects the internal organs form mechanical insults, and defends the human body from pathogenic microbes, UV-irradiation and free radicals. Of course, the skin also has homeostatic control system; so called 'barrier repair response' (Fig. 1b). When the barrier is compromised by either external insult or abnormal nutritional supplement, such as seen in the essential fatty acid deficiency (EFAD) model, the homeostatic response includes increasing lamellar body (LB) secretion and epidermal lipid synthesis [18].

The initiation of the epidermal barrier repair response depends on a certain signal and several signals have been suggested as possible candidates. Firstly, increased transepidermal water loss (TEWL) and subsequent changes in osmotic pressure of epidermal keratinocyte were suggested as regulatory signals for barrier homeostasis. A series of experiments using animal models, however, showed that, when the barrier-perturbed skin was immersed in aqueous solution, the tonicity of the solution did not affect the barrier recovery rate, which suggests that the change of tonicity is not a primary signal for barrier homeostasis [15]. Increased secretion and synthesis of epidermal cytokines, subsequent to barrier abrogation, was also observed in both human and murine skin [31]. The cytokines are one of the most characterized classes of signaling molecules and they regulate downstream processes of barrier homeostasis, such as keratinocyte proliferation and lipid synthesis [9]. However, the blockade of permeability barrier recovery using a water vapor impermeable membrane did not prevent the change of epidermal cytokine expression, suggesting that the cytokines are not primary signaling molecules for barrier homeostasis.

$\mathrm{Ca}^{2+}$ acts as a major regulator in keratinocyte differentiation and proliferation and is thought to be a main signal transducer for skin barrier homeostasis. The concentration gradient of $\mathrm{Ca}^{2+}$ within the epidermis, with its highest levels in the stratum granulosum (SG) and lowest levels in the basal cell layer [23], is important for both permeability barrier homeostasis and epidermal differentiation. Barrier disruption causes an immediate depletion of both intracellular and extracellular calcium ions in the SG, resulting in the loss of the normal epidermal calcium gradient [20, 22, 24]. Previously, Mauro et al. [22] showed that the peak $\mathrm{Ca}^{2+}$ concentrations within the outer epidermis fell from $460 \pm 57 \mathrm{mg}$ per $\mathrm{kg}$ to $128 \pm 14 \mathrm{mg}$ per kg immediately after barrier disruption. Along with the permeability barrier recovery, the calcium ion concentration in the SG also increased and immersion of the barrier-perturbed skin into a calcium ion-containing solution delayed barrier recovery, suggesting a role for calcium ions in epidermal permeability barrier homeostasis. The crucial role of $\mathrm{Ca}^{2+}$ in barrier homeostasis was also shown by the observation that LB secretion can be manipulated by changes in $\mathrm{Ca}^{2+}$ by iontophoresis and sonophoresis, independent of barrier abrogation. These studies suggest that changes of epidermal calcium can be an important signal transducer for barrier repair in vivo, independent of changes in barrier function [17].

However, most of the above studies mention the role of calcium ions in cutaneous barrier functions as extracellular calcium gradient or intracellular free calcium level $\left(\left[\mathrm{Ca}^{2+}\right]_{\mathrm{i}}\right)$, separately. While the decrease of extracellular calcium ion concentration after barrier disruption can be explained by the passive outward calcium ion displacement induced by increased transcutaneous water loss, the exact mechanism underlying the decrease in $\left[\mathrm{Ca}^{2+}\right]_{\mathrm{i}}$ in response to lowered extracellular calcium ion concentration is still not clear.

There is a substantial and precisely controlled difference between intracellular free calcium ions and extracellular calcium ion concentration, and the extracellular free calcium level $\left(\left[\mathrm{Ca}^{2+}\right]_{\mathrm{o}}\right)$ is usually much higher than $\left[\mathrm{Ca}^{2+}\right]_{i}[21]$. Several different mechanisms are involved in regulating physiological $\left[\mathrm{Ca}^{2+}\right]_{i}$, such as plasma membrane $\mathrm{Ca}^{2+}$ channels, plasma membrane calcium ATPase (PMCA), sarco-endoplasmic membrane calcium ATPase (SERCA), and $\mathrm{Na}+-\mathrm{H}+$ exchangers (NHEs). Calcium ions, localized intracellularly, are stored within organelles, usually the endoplasmic reticulum (sarcoplasmic reticulum in muscle cells), where it is bound to molecules like calreticulin. Due to the above mentioned mechanisms, the concentration of free $\mathrm{Ca}^{2+}$ within the cell is usually very low. 


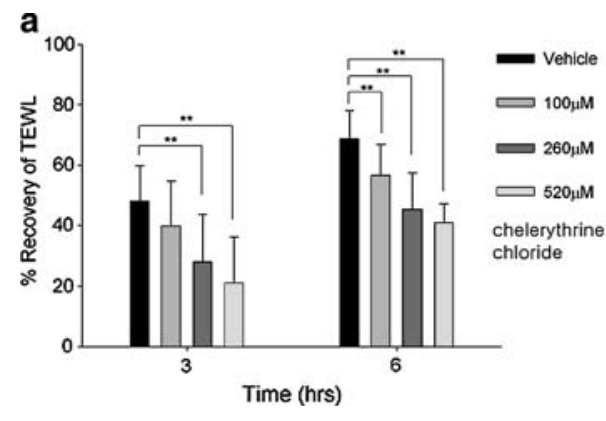

Fig. 2 Broad-type PKC inhibitors and specific PKC $\delta$ inhibitor delay the barrier recovery. a Topical application of chelerythrine chloride, a broad-type PKC inhibitor, delayed the barrier recov-

But, in the uppermost SG layer, an influx of calcium ions as a trigger for terminal differentiation takes place and a higher $\left[\mathrm{Ca}^{2+}\right]_{\mathrm{i}}$ than that of the lower SG layers is observed.

The mechanism of increased $\left[\mathrm{Ca}^{2+}\right]_{\mathrm{i}}$ in the upper SG layer in response to the elevation of extracellular calcium is understood by degrees [28]. Previous studies [2, $10,30]$ suggested that the extracellular calcium-sensing receptor $(\mathrm{CaR})$ is involved in mediating calcium signaling during keratinocyte differentiation. Activation of $\mathrm{CaR}$ with calcium or other multivalent cations activates the phospholipase $\mathrm{C}$ signaling pathway, resulting in the generation of inositol 1, 4, 5-trisphosphate, the release of calcium from intracellular stores $[4,14]$ and a subsequent increase in calcium influx through nonspecific cation channels and a storage-operated calcium channel. This is followed by the activation of PKC [18] and elevated expression of differentiation-related genes such as loricrin, profilaggrin, and transglutaminase [5]. During the differentiation process of keratinocytes, PKC activation not only precedes the expression of differentiation markers but also induces differentiation $[5,6,8,17]$. And the specific PKC isotype, PKC $\alpha$, has been implicated in this process $[5,6,16]$.

We hypothesized that the decrease of $\left[\mathrm{Ca}^{2+}\right]_{\mathrm{i}}$ might be mediated by some signal transducers during the acute barrier disruption, just as the increase of $\left[\mathrm{Ca}^{2+}\right]_{\mathrm{i}}$ is mediated by receptors and signal transducers (such as $\mathrm{CaR}$, phospholipase $\mathrm{C}$ and $\mathrm{PKC}$ ) during terminal differentiation. Murata et al. demonstrated that both serine-palmitoyl transferase and glucosylceramide synthetase expression were increased through a PKCdependent mechanism in cultured human keratinocytes. ${ }^{1}$ This result provides a hint that PKC may be a

\footnotetext{
${ }^{1}$ S Murata, Y. Uchida, S. Ichikawa, Y Hirabayashi, W.M. Holleran: Regulation of Glucosylceramide synthase expression in cultured Human Keratinocytes. J Invest Dermatol 114: 795, 2000 (abstr.).
}

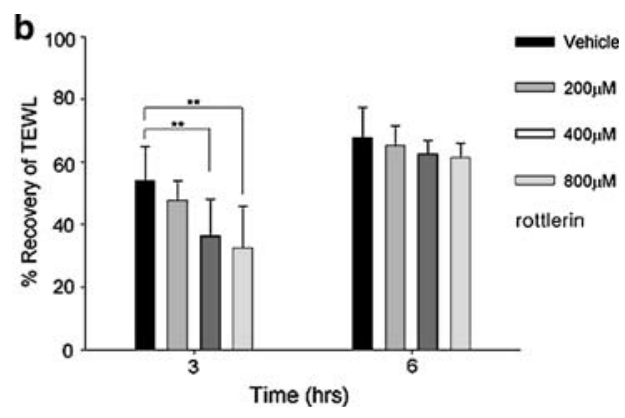

ery rate in a dose-dependent manner. b The percent recovery of TEWL in rottlerin-treated skin was also decreased in a dosedependent manner $(* * P<0.01)$

key candidate signal transducer for the decrease of $\left[\mathrm{Ca}^{2+}\right]_{\mathrm{i}}$. So, we investigated the effects of PKC inhibitors on the barrier recovery [1]. Our results show that both a broad-type PKC inhibitor and a specific PKC $\delta$ inhibitor reduced barrier recovery (Fig. 2), specifically through the inhibition of the $\left[\mathrm{Ca}^{2+}\right]_{\mathrm{i}}$ decrease by PKC (especially $\mathrm{PKC} \delta$ ) (Fig. 3). While both a broad-type PKC inhibitor and a specific PKC $\delta$ inhibitor showed the inhibitory effect on the decrease of $\left[\mathrm{Ca}^{2+}\right]_{i}$ after lowering $\left[\mathrm{Ca}^{2+}\right]_{\mathrm{o}}$, as shown in Figs. 3b, c, the intracellular calcium responses to chelerythrine chloride (broadtype PKC inhibitor) is slightly different from that of rottlerin (specific PKC $\delta$ inhibitor). The calcium trace of chelerythrine chloride-treated keratinocytes showed an unstable and increasing baseline. And when the extracellular calcium level was increased, the increase of calcium trace of chelerythrine chloride was slower than that of rottlerin. Because this type of calcium trace can be shown for unregulated calcium influx such as with the cytotoxic effect, we measured the cytotoxicity of chelerythrine chloride and rottlerin in cultured keratinocytes by the Alamar Blue ${ }^{\mathrm{TM}}$ assay. This study showed less than ten percent cytotoxicity in the chelerythrine chloride-treated cell culture. But rottlerin didn't show any cytotoxicity at all. Although, the calcium trace of chelerythrine chloride showed an increasing baseline and slower increase, we think these features are secondary effects due to weak cytotoxicity which masks the typical calcium curve as shown in Fig. 3c. Also, because chelerythrine chloride is a broadtype PKC inhibitor, its effect could be the sum of other blocking effects from other isoenzymes of PKC other than delta.

The role of PKC in keratinocyte differentiation is well known, but until now, nothing was known about its role in the barrier recovery response, especially with regards to the decrease of $\left[\mathrm{Ca}^{2+}\right]_{i}$. But, a similar regulation of $\left[\mathrm{Ca}^{2+}\right]_{\mathrm{i}}$ is seen in cells other than keratinocytes, namely granulosa cells. Basic fibroblast growth factor 


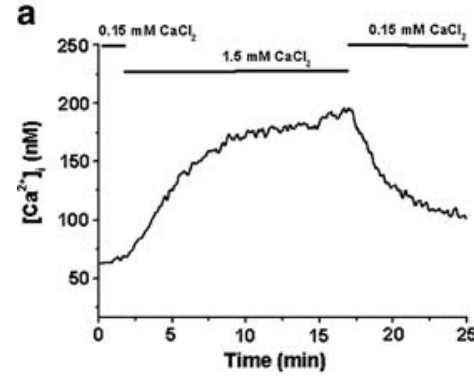

Fig. 3 Broad-type and delta-specific PKC inhibitors impede the decrease of $\left[\mathrm{Ca}^{2+}\right]$ i. a The increase $\left[\mathrm{Ca}^{2+}\right]$ o from 0.15 (HEPESbuffered low $\mathrm{Ca}^{2+}$ solution) to $1.5 \mathrm{mM}$ (HEPES-buffered high $\mathrm{Ca}^{2+}$ solution) induced an increase of $\left[\mathrm{Ca}^{2+}\right] \mathrm{i}$. And elevated $\left[\mathrm{Ca}^{2+}\right] \mathrm{i}$ returned to the baseline level after lowering $\left[\mathrm{Ca}^{2+}\right]$ o to $0.15 \mathrm{mM}$. b In the case of chelerythrine chloride-treated $(5 \mu \mathrm{M})$ keratinocytes, there was a slight increase in $\left[\mathrm{Ca}^{2+}\right] \mathrm{i}$ at baseline.

prevents granulosa cell apoptosis by decreasing $\left[\mathrm{Ca}^{2+}\right]_{\mathrm{i}}$ [19]. Peluso et al. [25] elucidated the mechanism through which bFGF-activated PKC $\delta$ regulates $\left[\mathrm{Ca}^{2+}\right]_{\mathrm{i}}$ within a physiological range by stimulating calcium efflux. They proposed that activated PKC functions as a serine/threonine phosphorylator of various molecular targets that may include calcium efflux regulators, such as PMCA. As shown in other cell types, TPA-dependent phosphorylation of PMCA enhances the rate of calcium efflux, thereby maintaining calcium homeostasis [13]. The PMCA pumps are localized in the plasma membrane, and their activities are influenced by PKC $[3,26,29]$. But, PKC $\delta$ is the only PKC isotype that is expressed by granulosa cells. The existence of PKC $\alpha, \delta$, $\varepsilon, \eta$ and $\zeta$ in keratinocytes is well-documented $[5,7,11$, 17] and other PKC isoforms (namely PKC $\beta, \gamma$, and $\mu$ ) were also found in various keratinocyte cell lines [11, 12, 27]. Among the normally existing PKC isoenzymes in keratinocytes, $\mathrm{PKC} \delta$ is a novel isoform of $\mathrm{PKC}$, and is DAG-sensitive but calcium-insensitive. These results suggest the role of PKC- $\delta$ as a signal mediator in epidermal permeability barrier homeostasis, especially in regulating intracellular calcium concentration.

Our suggested mechanism of calcium regulation by PKC is shown in Fig. 4. When the permeability barrier is disrupted, there is TEWL increase, followed by a decrease of the extracellular calcium level in the upper epidermis. The extracellular calcium loss is sensed and reported by an unknown receptor. This receptor may increase the level of DAG, an endogenous PKC activator, and activate PKC as a signal transducer. And this signal may regulate the decrease of $\left[\mathrm{Ca}^{2+}\right]_{\mathrm{i}}$ by stimulating calcium efflux through activation of an exchange channel or pump like PMCA. And then, the decrease of $\left[\mathrm{Ca}^{2+}\right]_{\mathrm{i}}$ induces a variety of responses for barrier repair such as LB secretion. However, in our proposed

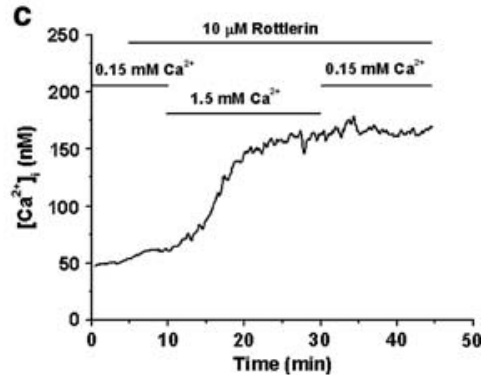

The increase of $\left[\mathrm{Ca}^{2+}\right]$ o from 0.15 to $1.5 \mathrm{mM}$ induced an increase in $\left[\mathrm{Ca}^{2+}\right] \mathrm{i}$ and the elevated $\left[\mathrm{Ca}^{2+}\right] \mathrm{i}$ did not return to the baseline level after lowering $\left[\mathrm{Ca}^{2+}\right]$ o to $0.15 \mathrm{mM}$. c In rottlerin-treated $(10 \mu \mathrm{M})$ keratinocytes, $\left[\mathrm{Ca}^{2+}\right] \mathrm{i}$ also did not return to the baseline and maintained the elevated $\left[\mathrm{Ca}^{2+}\right] \mathrm{i}$ even after lowering $\left[\mathrm{Ca}^{2+}\right] \mathrm{o}$ to $0.15 \mathrm{mM}$. The data in this graph represent the mean of ten cells

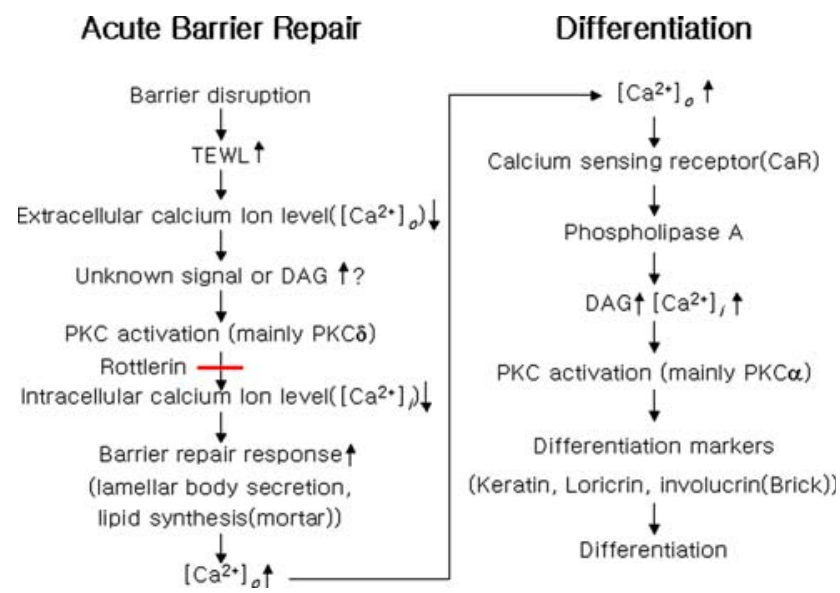

Fig. 4 Our model for the mechanism of intracellular calcium regulation by $\mathrm{PKC}$

homeostatic barrier control mechanism, there are missing links between the decrease of $\left[\mathrm{Ca}^{2+}\right]_{0}$ and the decrease of $\left[\mathrm{Ca}^{2+}\right]_{i}$ (Fig. 1c). As mentioned before, during keratinocyte differentiation, $\mathrm{CaR}$ senses the increase of $\left[\mathrm{Ca}^{2+}\right]_{\mathrm{o}}$ and nonspecific cation channels and storage- operating calcium channels increase $\left[\mathrm{Ca}^{2+}\right]_{\mathrm{I}}$. As in keratinocyte differentiation, there may be a receptor for sensing the decrease of $\left[\mathrm{Ca}^{2+}\right]_{0}$ and an effector for decreasing $\left[\mathrm{Ca}^{2+}\right]_{\mathrm{i}}$. Future studies are necessary to test this hypothesis and to find the receptor and effector. Previously, we have reported several techniques to induce LB secretion without permeability barrier abrogation. Currently, using similar methods, effects of selective modulation of epidermal calcium gradient on PKC- $\delta$ activation is under investigation. And these investigations may provide additional evidences for the role of PKC- $\delta$ as a signaling mediator in epidermal permeability barrier homeostasis. 


\section{References}

1. Ahn BK, Jeong SK, Kim HS, Choi KJ, Seo JT, Choi EH, Ahn SK, Lee SH (2006) Rottlerin, a specific inhibitor of protein kinase C-delta, impedes barrier repair response by increasing intracellular free calcium. J Invest Dermatol 126:1348-1355

2. Bikle DD, Ratnam A, Mauro T, Harris J, Pillai S (1996) Changes in calcium responsiveness and handling during keratinocyte differentiation. Potential role of the calcium receptor. J Clin Invest 97:1085-1093

3. Blaustein MP, Lederer WJ (1999) Sodium/calcium exchange: its physiological implications. Physiol Rev 79:763-854

4. Chattopadhyay N, Mithal A, Brown EM (1996) The calciumsensing receptor: a window into the physiology and pathophysiology of mineral ion metabolism. Endocr Rev 17:289-307

5. Denning MF, Dlugosz AA, Williams EK, Szallasi Z, Blumberg PM, Yuspa SH (1995) Specific protein kinase C isozymes mediate the induction of keratinocyte differentiation markers by calcium. Cell Growth Differ 6:149-157

6. Dlugosz AA, Yuspa SH (1993) Coordinate changes in gene expression which mark the spinous to granular cell transition in epidermis are regulated by protein kinase C. J Cell Biol 120:217-225

7. Dlugosz AA, Mischak M, Mushinski JF, Yuspa SH (1992) Transcripts encoding protein kinase $\mathrm{C}$ alpha, delta, epsilon, zeta, and eta are expressed in basal and differentiating mouse keratinocytes in vitro and exhibit quantitative changes in neoplastic cell. Mol Carcinog 5:286-292

8. Dlugosz AA, Cheng C, Williams EK, Dharia AG, Denning MF, Yuspa SH (1994) Alterations in murine keratinocyte differentiation induced by activated rasHa genes are mediated by protein kinase C-alpha. Cancer Res Dec 15; 54:64136420

9. Elias PM, Wood LC, Feingold KR (1999) Epidermal pathogenesis of inflammatory dermatoses. Am J Contact Dermat. 10:119-126

10. Filvaroff E, Calautti E, Reiss M, Dotto GP (1994) Functional evidence for an extracellular calcium receptor mechanism triggering tyrosine kinase activation associated with mouse keratinocyte differentiation. J Biol Chem 269:21735-21740

11. Fischer SM, Lee ML, Maldve RE et al (1993) Association of protein kinase $\mathrm{C}$ activation with ornithine decarboxylase in murine but not in human keratinocyte cultures. Mol Carcinog 7:228-237

12. Fisher GJ, Tavakkol A, Leach K et al (1993) Differential expression of protein kinase $\mathrm{C}$ isoenzymes in normal and psoriatic adult human skin: reduced expression of protein kinase C-betaII in psoriasis. J Invest Dermatol 101:553-559

13. Garcia ML, Strehler EE (1999) Plasma membrane calcium ATPases as critical regulators of calcium homeostasis during neuronal cell function. Front Biosci 4:D869-D882

14. Garrett JE, Capuano IV, Hammerland LG et al (1995) Molecular cloning and functional expression of human parathyroid calcium receptor cDNAs. J Biol Chem 270:12919-12925

15. Lee SH, Elias PM, Proksch E, Menon GK, Mao-Quiang M, Feingold KR (1992) Calcium and potassium are important regulators of barrier homeostasis in murine epidermis. J Clin Invest 89:530-538
16. Lee YS, Dlugosz AA, McKay R, Dean NM, Yuspa SH (1997) Definition by specific antisense oligonucleotides of a role for protein kinase $\mathrm{C}$ alpha in expression of differentiation markers in normal and neoplastic mouse epidermal keratinocytes. Mol Carcinog 18:44-53

17. Lee YS, Yuspa SH, Dlugosz AA (1998) Differentiation of cultured human epidermal keratinocytes at high cell densities is mediated by endogenous activation of the protein kinase $\mathrm{C}$ pathway. J Invest Dermatol 111:762-766

18. Lee SH, Jeong SK, Ahn SK (2006) An update of the defensive barrier function skin. Yonsei Med J 47:293-306

19. Lynch K, Fernandez G, Pappalardo A, Peluso JJ (2000) Basic fibroblast growth factor inhibits apoptosis of spontaneously immortalized granulosa cells by regulating intracellular free calcium levels through a protein kinase $\mathrm{C}$ delta dependent pathway. Endocrinology 141:4209-4217

20. Mao-Qiang M, Mauro T, Bench G, Warren R, Elias PM, Feingold KR (1997) Calcium and potassium inhibit barrier recovery after disruption, independent of the type of insult in hairless mice. Exp Dermatol 6:36-40

21. Mauro T (2003) The discovery channel': CRAC'king the code of calcium influx. J Invest Dermatol. 121:IX-X

22. Mauro T, Bench G, Sidderas-Haddad E, Feingold K, Elias P, Cullander C (1998) Acute barrier perturbation abolishes the $\mathrm{Ca}^{++}$and $\mathrm{K}^{+}$gradients in murine epidermis: quantitative measurement using PIXE. J Invest Dermatol 111:1198-1201

23. Menon GK, Feingold KR, Moser AH, Brown BE, Elias PM (1985) De novo sterologenesis in the skin. II. Regulation by cutaneous barrier requirements. J Lipid Res 26:418-427

24. Menon GK, Elias PM, Lee SH, Feingold KR (1992): Localization of calcium in murine epidermis following disruption and repair of the permeability barrier. Cell Tissue Res 270:503-512

25. Peluso JJ, Pappalardo A, Fernandez G (2001) Basic fibroblast growth factor maintains calcium homeostasis and granulosa cell viability by stimulating calcium efflux via a PKC-dependent pathway. Endocrinology 142:4203-4211

26. Philipson KD, Nicoll DA (2000) Sodium-calcium exchanger: a molecular prespective. Annu Rev Physiol 62:111-133

27. Rennecke J, Johannes FJ, Richter KH, Kittstein W, Marks F, Gschwendt M (1996) Immunological demonstration of protein kinase $\mathrm{C} \mu$ in murine tissues and various cell lines. Differential recognition of phosphorylated forms and lack of down-regulation upon 12-O-tetradecanoylphorbol-13-acetate treatment of cells. Eur J Biochem 242:428-432

28. Sharpe GR, Gillespie JI, Greenwell JR (1989) An increase in intracellular free calcium is an early event during differentiation of cultured human keratinocytes. FEBS 254:25-28

29. Therien AG, Blostein R, (2000) Mechanisms of sodium pump regulation. Am J Physiol Cell Physiol 279:C541-C566

30. Tu CL, Oda Y, Bikle DD (1999) Effects of a calcium receptor activator on the cellular response to calcium in human keratinocytes. J Invest Dermatol 113:340-345

31. Wood LC, Elias PM, Calhoun C, Tsai JC, Grunfeld C, Feingold KR (1996) Barrier disruption stimulates interleukin1expression and release from a pre-formed pool in murine epidermis. J Invest Dermatol 106:397-403 